\title{
Metaplastic carcinoma of the breast: Clinicopathological features and treatment outcomes with long-term follow up
}

\author{
ARON GORTMAN $^{1}$, NOEL J. AHERNE ${ }^{1-3}$, JUSTIN WESTHUYZEN ${ }^{1}$, JULAN V. AMALASEELAN ${ }^{4}$, \\ PATRICK M. DWYER ${ }^{4}$, MATTHEW HOFFMANN ${ }^{5}$, ANDREW T. LAST ${ }^{5}$ and THOMAS P. SHAKESPEARE ${ }^{1,2}$ \\ ${ }^{1}$ Department of Radiation Oncology, Mid North Coast Cancer Institute; ${ }^{2}$ Rural Clinical School, Faculty of Medicine, \\ University of New South Wales; ${ }^{3}$ School of Health and Human Sciences, Southern Cross University, Coffs Harbour, New \\ South Wales 2450; ${ }^{4}$ Department of Radiation Oncology, North Coast Cancer Institute, Lismore, New South Wales 2480; \\ ${ }^{5}$ Department of Radiation Oncology, Mid North Coast Cancer Institute, Port Macquarie, New South Wales 2444, Australia
}

Received September 8, 2020; Accepted February 15, 2021

DOI: $10.3892 / \mathrm{mco} .2021 .2340$

\begin{abstract}
Metaplastic breast carcinoma is an uncommon subtype of invasive ductal carcinoma with a tendency towards poorer clinical outcomes. Following ethical approval, the current study reviewed the institutional records of $\sim 2,500$ women with breast cancer. A total of 14 cases of metaplastic breast cancer were reviewed for management and treatment outcomes. The results demonstrated that patients had median follow up of 30 months, a 5-year disease-free survival of $57.1 \%$ and 5-year overall survival of $57.1 \%$. The majority of patients had at least T2 disease and all tumours were high grade. Additionally, most patients were triple negative and nodal metastases were uncommon. Metaplastic breast cancer is an aggressive variant of invasive breast cancer. Most patients can be treated with breast conservation and survival parameters tend to be worse than more common breast cancer subtypes.
\end{abstract}

\section{Introduction}

Metaplastic breast carcinoma $(\mathrm{MpBC})$ is an uncommon breast cancer subtype that comprises less than $1 \%$ of all breast malignancies (1-5). MpBC was first described in 1973 by Huvos et al and was formally recognised as a distinct pathological subtype of breast cancer in $2000(1,6)$. Histopathological subtyping of $\mathrm{MpBC}$ is complex, and may be characterised by differentiation of the invasive epithelium into a spectrum of squamous and mesenchymal elements and may be composed entirely of metaplastic elements or by a mixture of both metaplastic and carcinomatous regions $(1,2,7)$. The 2012 WHO classification system of phenotypes of metaplastic breast carcinoma includes low grade adenosquamous carcinoma, fibromatosis-like

Correspondence to: Dr Noel J. Aherne, Department of Radiation Oncology, Mid North Coast Cancer Institute, Coffs Harbour, New South Wales 2450, Australia

E-mail: noel.aherne@health.nsw.gov.au

Key words: breast cancer, metaplastic, radiation, triple negative metaplastic carcinoma, squamous cell carcinoma, spindle cell carcinoma, and metaplastic carcinoma with mesenchymal differentiation (1).

Metaplastic breast carcinoma typically presents with high histological grade, and the majority exhibit triple negative receptor expression (1-5,8). In addition, $\mathrm{MpBC}$ tends to be diagnosed at a higher tumour stage than non-metaplastic invasive ductal carcinomas, with a greater mean tumour size reported by WHO, while simultaneously being less likely to have axillary nodal involvement (1-6,9-11). Distant metastases are frequently found in the absence of lymph node metastases in $\mathrm{MpBC}$, most commonly in the brain and lungs $(1,3,12,13)$.

The evidence for management in $\mathrm{MpBC}$ is largely reliant on the results of a small number of single institution case series, and $\mathrm{MpBC}$ tends to be managed similarly to that of the more common invasive ductal carcinomas (IDC). The aggressive, complex, and frequently unpredictable clinicopathological presentation of $\mathrm{MpBC}$ may argue for more aggressive management for local, regional, and distant control.

In this case series, we report on 14 patients with $\mathrm{MpBC}$ who were treated in our institution with curative intent. We discuss the clinical and histopathological features, treatment strategies, and clinical outcomes to date.

\section{Subjects and methods}

Ethical approval.Following North Coast NSW Human Research Ethics Committee approval (reference 2019/ETH12207; individual consent for this retrospective analysis was waived), the study was undertaken to review our institutional experience in the management of $\mathrm{MpBC}$.

Subjects. A total of 14 patients with MpBC from our three integrated comprehensive cancer centres who received curative intent radiation therapy between January 2009 and January 2020 were included.

Methods. We reviewed age at diagnosis, gender, tumour laterality, tumour size, axillary nodal status, presence of lymphovascular invasion (LVI), histological grade, receptor status [estrogen receptor (ER); progesterone receptor (PR); 
human epidermal growth factor receptor 2 (HER-2)], immunohistochemistry (IHC), Ki-67 prognostic index, as well as $\mathrm{MpBC}$ subtype. We also reviewed the radiation therapy fractionation and radiation field, extent of surgery, and details of systemic therapy. We have previously published our treatment techniques and outcomes for patients with breast cancer (14-17). Tumour and nodal staging was based on findings at wide local excision or mastectomy, or in the case of neoadjuvant systemic therapy, based on radiological findings in addition to the pathological specimen.

\section{Results}

Patient data. A total of 14 female patients from 2009-2020 who were diagnosed with $\mathrm{MpBC}$ in the curative setting were included in this case series. The median age at diagnosis was 66 years. The median follow up time post-completion of radiation therapy was 30.1 months. In total, 12 of the 14 patients underwent staging with either one or all of body CT, whole body bone scan or positron emission tomography CT scan.

Clinicopathological features. Clinicopathological features of the patients are summarised in Table I. Based on the World Health Organisation classifications of tumours of the breast (1), the most common $\mathrm{MpBC}$ subtypes were pure spindle cell carcinoma or pure squamous cell carcinoma. The majority of tumours $(42.9 \%)$ were $\mathrm{T} 2$, and the median tumour size was $34.5 \mathrm{~mm}$. Thirteen patients $(92.9 \%)$ were axillary node negative; one patient had 1 of 13 nodes positive at ALND. Lymphovascular invasion was identified in 3 of 14 patients (21.4\%). All tumours were high grade (grade 3 ). The tumours in 13 of 14 patients were triple negative. For those in whom a Ki-67 proliferation index was reported, the score ranged between 25 and $90 \%$ (mean index score $50 \%$ ).

Therapeutic regimens. All patients received radiation therapy; hypofractionation 40.05 Gray/15 fractions was the most common schedule. All patients who received radiation therapy in this study received intensity modulated radiation therapy (IMRT). Most patients were suitable for breast conservation surgery.

A total of 12 patients received chemotherapy and 2 either declined or were not offered chemotherapy. The most common chemotherapeutic regimens were adriamycin and taxol based, followed by taxol and cyclophosphamide regimens; one patient received the fluorouracil epirubicin cyclophosphamide-docetaxel (FEC-D) regimen. One patient received trastuzumab for HER-2 positive disease, and one patient letrozole for a mixed tumour with a triple positive IDC.

Clinical outcomes. Regarding follow up status, ten patients $(71.4 \%)$ were alive and disease free at the time of publication. There were three patients $(21.4 \%)$ who died from cancer progression, one patient has been lost to follow up. Of the three patients who died due to progressive disease, one of these presented with radiological T4 disease and underwent mastectomy and post mastectomy radiation therapy (PMRT); there was disease recurrence 4 months post-RT in the left chest wall scar site, and the patient subsequently underwent palliative RT to the sites of bony disease. This patient died
4 months afterwards. The second patient also had T4 disease and underwent radiation therapy to the breast and SCF after poor response to neoadjuvant chemotherapy, which was subsequently followed by mastectomy. The patient died 5 months later. The third of these patients experienced recurrence 32 months post-RT in the ipsilateral left chest wall, confirmed on histopathology, prior to developing distant disease.

The 5-year disease-free survival (DFS) was 57.1\% and 5 -year overall survival (OS) was $57.1 \%$, as one patient who experienced local recurrence has unknown current clinical status. The 4 year DFS and OS were both $66.7 \%$.

\section{Discussion}

Metaplastic breast cancer is an aggressive, uncommon variant of breast cancer that may have unpredictable clinical behaviour. Classification of various subtypes of $\mathrm{MpBC}$ is complex and there are often overlapping features seen on histopathology. Metaplastic carcinoma has been described as having lower response rates to systemic therapy, or frequently being chemoresistant (1-6,8,10,18-24).

Similar to other cases series, the majority of MpBC cases in this study presented with a tumour size of T2 or greater $(3,5-9,25)$. There was a low incidence of axillary nodal metastases, which has been repeatedly reported since the earliest descriptions of the clinicopathological features of $\operatorname{MpBC}(3,5,10,11)$. The high incidence of distant metastases in the presence of low rates of nodal involvement has been extensively described, supporting the hypothesis that MpBC disseminates via the haematogenous route rather than via the lymphatic system $(1,2,13,19,21,25-30)$. Although higher rates of mastectomy in $\mathrm{MpBC}$ relative to the more common invasive ductal carcinoma (IDC) have been reported in the literature $(3,5,10,18-20)$, in our series a similar proportion of patients had breast conservation versus mastectomy.

Several reports have concluded that metaplastic carcinoma shares a similar basal phenotype to triple negative breast cancer (TNBC) and to the claudin-low molecular subtype $(2,10,31-33)$. The WHO reports that greater than $90 \%$ of $\mathrm{MpBC}$ exhibit triple negative receptor expression (1) and this is supported by the other results of other retrospective studies $(1,3,5)$. Our series included two patients with a HER-2 positive component.

Immunohistochemistry (IHC) for $\mathrm{MpBC}$ is critical not only for diagnosis and prognosis, but also for distinguishing between the various subtypes of MpBC. IHC for expression of high molecular weight cytokeratins (and basal markers) such as CK5/CK6, 34betaE12, AE1/AE3, E-Cadherin, CK14 and EGFR, are considered to be particularly important prognostic markers $(2,7,34)$. Low molecular weight keratins are often negative (1). McCart Reed et al performed molecular analysis of $347 \mathrm{MpBC}$ cases, and found that the majority of MpBC express EGFR, and EGFR overexpression was seen on molecular analysis to be associated with poor survival outcomes (7).

Although MpBC tends to be treated in a similar fashion to the more common breast carcinoma subtypes, disease-free survival and overall survival are significantly worse. It has been suggested that locoregional management may often not be optimised if based on the same tumour and nodal staging system as for the more common IDC $(5,11,13,25,35,36)$. 
Table I. Clinicopathological features of patients with $\mathrm{MpBC}$ $(\mathrm{n}=14)$.

\begin{tabular}{lc}
\hline Characteristic & $\mathrm{N}(\%)$ \\
\hline Histological subtype & \\
Adenosquamous & $0(0)$ \\
Fibromatosis-like & $1(7.1)$ \\
Pure spindle cell & $3(21.4)$ \\
Pure squamous cell carcinoma & $3(21.4)$ \\
Pure mesenchymal differentiation & $2(14.3)$ \\
Mixed & $3(21.4)$ \\
MpBC with no specific differentiating features & $2(14.3)$ \\
TNM Tumour Stage & \\
T1 & $3(21.4)$ \\
T2 & $6(42.9)$ \\
T3 & $3(21.4)$ \\
T4 & $2(14.3)$ \\
TNM Nodal Stage & \\
N0 & $13(92.9)$ \\
N1 & $1(7.1)$ \\
Surgery & \\
Wide Local Excision & $8(57.1)$ \\
Mastectomy & $6(42.9)$ \\
Sentinel Node Biopsy & $9(64.3)$ \\
Axillary Dissection & $3(21.4)$ \\
Radiation & \\
Primary Site & $12(85.7)$ \\
Nodal Irradiation & $2(14.3)$ \\
Tumour Cavity Boost & $6(42.9)$ \\
Hypofractionation & $11(78.6)$ \\
Conventional fractionation & $3(21.4)$ \\
\hline
\end{tabular}

$\mathrm{MpBC}$, metaplastic breast carcinoma.

Five-year overall survival rates have been estimated to be between 49-69\% (5,10,12-13,22,35,37-39).

The survival of MpBC patients reported in institutional studies is summarised in Table II. In general, MpBC patients experienced greater disease recurrence and poorer overall survival compared to both triple negative IDC and general IDC (10,12,13,37-39). Benson et al reported on 7 patients with $\mathrm{MpBC}$ from a single institution in India, in which all patients underwent mastectomy followed by PMRT and adjuvant chemotherapy (40). Three of seven patients were alive and well at last follow up at 5 years, one patient developed liver metastasis at 6 years post treatment, and three were lost to follow up.

WHO recognises a number of $\mathrm{MpBC}$ subtypes. The low-grade adenosquamous phenotype is typified by well-developed glandular and tubular formation, generally in an admixture with solid nests of squamous cells in a spindle celled background. Lymphocytes may often be seen in clusters $(1,2)$. The fibromastosis-like phenotype is typically characterised by a prominent 'fibromatosis-like' stroma characterised by bland spindled cells in a collagenous background including some foci of dense eosinophilic keloidal type collagen, and often with features of squamous differentiation including cytoplasmic keratinisation $(1,2)$. In the squamous cell carcinoma variant, negative IHC staining for SCC of other primary origins is critical $(2,41,42)$. SCC often consists of a cellular population of partly cystic cells with squamous differentiation, staining triple negative, adjacent to high grade invasive ductal cells, and therefore, is often a mixed phenotype. A conspicuous stromal reaction may often be described $(1,2,41)$. For the spindle cell carcinoma variant, in addition to the presence of atypical spindle cell proliferation or proliferation of spindle cells, and areas of focal necrosis, a concurrent invasive ductal carcinoma or in situ component is commonly found to be diagnostic. Common myoepithelial markers such as p63, smooth muscle actin (SMA), C10, as well as calponin, may be diagnostic $(1,2,42,43)$. Subtypes of mesenchymal differentiation, are often described as larger tumours $(2,44)$. Many cases of mesenchymal differentiation present with one or more of chondroid, osseous, rhabdomyoid, or other elements, or mixed in with other differentiation $(1,2)$. The term 'matrix producing carcinoma' has often been applied to MpBCs with mesenchymal elements (1). S100 may be used to confirm the presence of a matrix producing carcinoma (45).

A large proportion of $\mathrm{MpBC}$ display a mixture of elements, and ideally, each distinct element will be documented in the patient record. There are often conflicting reports about the relative aggression of the different subtypes of $\mathrm{MpBC}$; specifically, with regards to their predilection for axillary nodal and distant involvement $(6,13,19,35,46-49)$. Mixed pathologies may be more aggressive and have been associated with shorter DFS in some studies, and increasing numbers of morphologies in a mixed case may confer a survival disadvantage $(7,38,39)$.

Several patients in this case series had unique presentations. One patient was diagnosed after histopathology from removal of a leaking implant capsule demonstrated $\mathrm{MpBC}$, and was managed as occult disease. Given that it was not possible to see where the tumour was resected, this patient was not offered a breast boost. A second patient had low grade follicular lymphoma in a sentinel node that was CD20, CD21, and BCL2/BCL6 positive. A third patient had squamous cell carcinoma variant on WLE specimen and adenosquamous phenotype in the ALND specimen. Nodal involvement with different elements from the primary tumour in $\mathrm{MpBC}$ is not an uncommon finding $(6,11,50)$. A fourth patient with fibromatosis-like variant, which while described as typically low grade, was grade 3 in this specimen $(1,2)$.

It has been proposed that $\mathrm{MpBC}$ could be a particularly radiosensitive form of breast cancer (51). One patient in this study who presented with the mesenchymal differentiation phenotype had a $90 \mathrm{~mm}$ (T4) tumour extending into the pectoralis muscle, and radiological evidence of intramammary nodes. This patient underwent 2 cycles of neoadjuvant chemotherapy which was not well tolerated, and subsequently proceeded to radiation therapy with a fractionation of $48.06 \mathrm{~Gy} / 18$ fractions to the breast and $40.05 \mathrm{~Gy} / 15$ to the SCF. The pathological specimen from mastectomy showed only a single small focus of residual cancer next to adjacent scar tissue, enabling the mastectomy procedure to be fully clear of all margins (this patient, however, developed distant disease 6 months later). The American Society for Radiation Oncology (ASTRO) breast guidelines has proposed that the 
Table II. Survival of patients with MpBC: Comparisons of institutional studies.

\begin{tabular}{|c|c|c|c|c|}
\hline Author, year & $\begin{array}{l}\text { Number of } \\
\text { MpBC cases }\end{array}$ & 5-year DFS/PFS/RFS/LRR & 5-year OS in & (Refs.) \\
\hline Jung et al, 2010 & 35 & $\begin{array}{l}5 \text {-year DFS of } 41.8 \text { vs. } 81.8 \% \\
\text { in the TNBC group and } 87.3 \% \text { in } \\
\text { IDC overall }\end{array}$ & $\begin{array}{l}62.8 \text { vs. } 87.0 \% \text { in the } \\
\text { TNBC group, and } 92.0 \% \\
\text { in IDC overall }\end{array}$ & (10) \\
\hline Jin et al, 2018 & 26 & 5 -year DFS of $53.8 \%$ & $61.5 \%$ & $(37)$ \\
\hline Esbah et al, 2012 & 14 & 3 -year PFS of $33 \%$ & $56 \%$ & $(12)$ \\
\hline Fayaz et al, 2017 & 31 & 5 -year PFS of $50 \%$ & $69 \%$ & (39) \\
\hline Cimino-Mathews et al, 2016 & 45 & 5 -year RFS of $64 \%$ & $69 \%$ & (38) \\
\hline Leyrer et al, 2017 & 113 & 5 -year LRR of $21 \%$ & $69 \%$ & (13) \\
\hline
\end{tabular}

MpBC, metaplastic breast carcinoma; DFS, disease-free survival rate; PFS, progression-free survival rate; LRR, local-regional recurrence rate rate; RFS, recurrence free survival; OS, overall survival rate; IDC, invasive ductal carcinomas; TNBC, triple negative breast cancer.

radiobiological alpha: Beta ratio (a measure of cell sensitivity to changes in radiation fraction size) of metaplastic carcinoma is much higher than that of the more common IDC and that conventional fractionation could provide better control (44). In our series, 2 of 3 patients in total who received conventionally fractionated radiation remain alive (1 had WLE, 1 had mastectomy). Consideration of upfront radiation for larger lesions could therefore be an appropriate treatment strategy.

The recently published study by Moreno and colleagues from MD Anderson Cancer Center, which looked at 2,084 cases from the National Cancer Database from 2010-2014 and compared features of MpBC to both TNBC and other breast cancer subtypes, is the largest known study to date of $\mathrm{MpBC}$ (5). Patients with $\mathrm{MpBC}$ were observed to have worse OS at every clinical stage relative to both TNBC and other breast cancer subtypes. The investigators noted that on multivariate analysis, radiation therapy was a significant predictor for survival, with those who received radiation $30 \%$ less likely to die than those who did not receive radiation. The authors also noted that axillary nodal irradiation was slightly less used in $\mathrm{MpBC}$ compared to other breast cancer subtypes, with radiation utilised in $26.1 \%$ of $\mathrm{MpBC}$ cases targeting both breast/chest wall and regional nodes versus $33.7 \%$ in other breast cancer subtypes (not including TNBC). This is not unexpected, given that there is in general a lower predilection for nodal spread in $\mathrm{MpBC}$ relative to other breast cancer subtypes, as previously described. On multivariate analysis, treatment of regional nodes in addition to the breast or chest wall did not significantly influence outcomes in $\mathrm{N} 0$ or $\mathrm{N}^{+}$disease. The conclusion of the authors was that it is reasonable to consider more extensive locoregional treatment in the form of axillary radiation therapy on a case by case basis.

Radiation therapy was delivered to half of the patients (54\% of 113) in the study of Leyrer et al, who concluded on multivariate analysis that radiation therapy was the only factor correlating with reduced locoregional recurrence (13). There was a relative risk of 3.1 without radiation therapy, (CI, 1.13-9.88, $\mathrm{P}=0.027$ ). Moreover, of the 47 patients who underwent radiation therapy, $40 \%$ received nodal irradiation. Of 36 patients who had breast conserving therapy who received radiation therapy, only 1 case had local recurrence. Not having radiation therapy after resection was associated with an increased relative risk of 3.3 for LRR. Tseng and Martinez, analysing the SEER database of MpBC cases, concluded that radiation improved both DFS and OS for all patients undergoing treatment for $\mathrm{MpBC}$ (35). This was irrespective of the type of surgical procedure performed, with 36 and $26 \%$ decreases in death from any cause and breast-related mortality, respectively. Multivariate analyses demonstrated 38 and $34 \%$ decreases in death from any cause and breast-related mortality, respectively.

The use of PMRT in earlier stage MpBC is not fully elucidated, given the relatively rarity of the disease. There may be similarities with other series of outcomes in triple negative breast cancer. The study from 2011 by Wang et al randomised 681 Chinese women with Stage I-II disease who received mastectomy for TNBC to either adjuvant chemotherapy alone or chemotherapy in combination with PMRT, including nodal irradiation as indicated (27). The study demonstrated significant improvement in the group which received both chemotherapy and PMRT, with a 5-year RFS of $88.3 \%$ and OS of $90.4 \%$, respectively, versus 78.7 and $74.6 \%$ in the chemotherapy alone group. Multiple case studies have suggested that the traditional indications for PMRT could be broadened in MpBC $(5,21,34,35,40)$, while simultaneously acknowledging some limitations given the retrospective nature of these studies.

In this case series we have reviewed the clinicopathological outcomes of a small number of women who were treated for metaplastic breast cancer. We have reported on follow up, the unique findings on histopathology, and progress following multimodality management with a focus on radiation oncology outcomes. The use of extensive imaging in addition to standard mammography and ultrasound for staging appears to be particularly critical for metaplastic carcinoma, given its aggressive nature.

\section{Acknowledgements}

Not applicable. 


\section{Funding}

No funding was received.

\section{Availability of data and materials}

The datasets used and/or analysed during the current study are available from the corresponding author on reasonable request.

\section{Authors' contributions}

AG conceived and designed the current study. $\mathrm{MH}$ made a substantial contribution to the acquisition of data. AG, NJA, JW, JVA, PMD, ATL and TPS collected, assembled, analysed and interpreted the data and revised the manuscript critically for important intellectual content. AG and NJA confirmed the authenticity of all the data. All authors contributed to and approved the final manuscript.

\section{Ethics approval and consent to participate}

This retrospective review was approved by the North Coast NSW Human Research Ethics Committee (approval no. 2019/ETH12207). Consent for participation was not required.

\section{Patient consent for publication}

Not applicable.

\section{Competing interests}

The authors declare that they have no competing interests.

\section{References}

1. Reis-Filho JS, Lakhani SR, Gobbi H and Sneige N: Metaplastic carcinoma. WHO Classification of Tumours of the Breast. World Health Organization Classification of Tumours. Vol 4. 4th edition. International Agency for Research on Cancer, Lyon, pp48-52, 2012.

2. McMullen ER, Zoumberos NA and Kleer CG: Metaplastic breast carcinoma: Update on histopathology and molecular alterations. Arch Pathol Lab Med 143: 1492-1496, 2019.

3. Pezzi CM, Patel-Parekh L, Cole K, Franko J, Klimberg VS and Bland K: Characteristics and treatment of metaplastic breast cancer: Analysis of 892 cases from the national cancer data base. Ann Surg Oncol 14: 166-173, 2007.

4. Barnes PJ, Boutilier R, Chiasson D and Rayson D: Metaplastic breast carcinoma: Clinical-pathological characteristics and HER2/neu expression. Breast Cancer Res Treat 91: 173-178, 2005 .

5. Moreno AC, Lin YH, Bedrosian I, Shen Y, Babiera GV and Shaitelman SF: Outcomes after treatment of metaplastic versus other breast cancer subtypes. J Cancer 11: 1341-1350, 2020.

6. Huvos AG, Lucas JC Jr and Foote FW Jr: Metaplastic breast carcinoma. Rare form of mammary cancer. NY State J Med 73: 1078-1082, 1973.

7. McCart Reed AE, Kalaw E, Nones K, Bettington M, Lim M, Bennett J, Johnstone K, Kutasovic JR, Saunus JM, Kazakoff S, et al: Phenotypic and molecular dissection of metaplastic breast cancer and the prognostic implications. J Pathol 247: 214-227, 2019.

8. Bae SY, Lee SK, Koo MY, Hur SM, Choi MY, Cho DH, Kim S, Choe JH, Lee JE, Kim JH, et al: The prognoses of metaplastic breast cancer patients compared to those triple-negative breast cancer patients. Breast Cancer Res Treat 126: 471-478, 2011.
9. Beatty JD, Atwood M, Tickman R and Reiner M: Metaplastic breast cancer: Clinical significance. Am J Surg 191: 657-664, 2006.

10. Jung SY, Kim HY, Nam BH, Min SY, Lee SJ, Park C, Kwon Y, Kim EA, Ko KL, Shin KH, et al: Worse prognosis of metaplastic breast cancer patients than other patients with triple-negative breast cancer. Breast Cancer Res Treat 120: 627-637, 2010.

11. Oberman HA: Metaplastic carcinoma of the breast. A clinicopathologic study of 29 patients. Am J Surg Pathol 11: 918-929, 1987.

12. Esbah O, Turkoz FP, Turker I, Durnali A, Ekinci AS, Bal O, Sonmez OU, Budakoglu B, Arslan UY and Oksuzoglu B: Metaplastic breast carcinoma: Case series and review of the literature. Asian Pac J Cancer Prev 13: 4645-4649, 2012.

13. Leyrer CM, Berriochoa CA, Agrawal S, Donaldson A, Calhoun BC, Shah C, Stewart R, Moore HCF and Tendulkar RD: Predictive factors on outcomes in metaplastic breast cancer. Breast Cancer Res Treat 165: 499-504, 2017.

14. Gortman AM, Aherne NJ, Amalaseelan J, Last A, Westhuyzen J, Chamberlain L and Shakespeare TP: Long-term outcomes of patients with conserved breast cancer treated with adjuvant hypofractionated prone breast intensity-modulated radiation therapy. J Med Imaging Radiat Oncol 64: 845-851, 2020.

15. Wen S, Manuel L, Doolan M, Westhuyzen J, Shakespeare TP and Aherne NJ: Effect of clinical and treatment factors on survival outcomes of triple negative breast cancer patients. Breast Cancer (Dove Med Press) 12: 27-35, 2020.

16. Dean J, Hansen CJ, Westhuyzen J, Waller B, Turnbull K, Wood M and Last A: Tangential intensity modulated radiation therapy (IMRT) to the intact breast. J Med Radiat Sci 63: 217-223, 2016.

17. Mortimer JW, McLachlan CS, Hansen CJ, Assareh H, Last A, McKay MJ and Shakespeare TP: Use of hypofractionated post-mastectomy radiotherapy reduces health costs by over $\$ 2000$ per patient: An Australian perspective. J Med Imaging Radiat Oncol 60: 146-153, 2016.

18. Nelson RA, Guye ML, Luu T and Lai LL: Survival outcomes of metaplastic breast cancer patients: Results from a US population-based analysis. Ann Surg Oncol 22: 24-31, 2015.

19. Lee H, Jung SY, Ro JY, Kwon Y, Sohn JH, Park IH, Lee KS, Lee S, Kim SW, Kang HS, et al: Metaplastic breast cancer: Clinicopathological features and its prognosis. J Clin Pathol 65: 441-446, 2012.

20. Song Y, Liu X, Zhang G, Song H, Ren Y, He X, Wang Y, Zhang J, Zhang Y, Sun S, et al: Unique clinicopathological features of metaplastic breast carcinoma compared with invasive ductal carcinoma and poor prognostic indicators. World J Surg Oncol 11: 129-138, 2013.

21. Shah DR, Tseng WH and Martinez SR: Treatment options for metaplastic breast cancer. ISRN Oncol 2012: 706162, 2012.

22. Rayson D, Adjei AA, Suman VJ, Wold LE and Ingle JN: Metaplastic breast cancer: Prognosis and response to systemic therapy. Ann Oncol 10: 413-419, 1999.

23. Chen IC, Lin CH, Huang CS, Lien HC, Hsu C, Kuo WH, Lu YS and Cheng AL: Lack of efficacy to systemic chemotherapy for treatment of metaplastic carcinoma of the breast in the modern era. Breast Cancer Res Treat 130: 345-351, 2011.

24. Chao TC, Wang CS, Chen SC and Chen MF: Metaplastic carcinomas of the breast. J Surg Oncol 71: 220-225, 1999.

25. Böler DE, Kara H, Sağlıcan Y, Tokat F and Uras C: Metaplastic carcinoma of the breast: A case series and review of the literature. J Oncol Sci 2: 38-42, 2016.

26. Brenner RJ, Turner RR, Schiller V, Arndt RD and Giuliano A: Metaplastic carcinoma of the breast: Report of three cases. Cancer 82: 1082-1087, 1998.

27. Wang J, Shi M, Ling R, Xia Y, Luo S, Fu X, Xiao F, Li J, Long X, Wang $\mathrm{J}$, et al: Adjuvant chemotherapy and radiotherapy in triple-negative breast carcinoma: A prospective randomized controlled multi-centre trial. Radiother Oncol 100: 200-204, 2011.

28. Al-Hilli Z, Choong G, Keeney MG, Visscher DW, Ingle JN, Goetz MP and Jakub JW: Metaplastic breast cancer has a poor response to neoadjuvant systemic therapy. Breast Cancer Res Treat 176: 709-716, 2019.

29. Tzanninis IG, Kotteas EA, Ntanasis-Stathopoulos I, Kontogianni P and Fotopoulos G: Management and outcomes in metaplastic breast cancer. Clin Breast Cancer 16: 437-443, 2016.

30. McKinnon E and Xiao P: Metaplastic carcinoma of the breast. Arch Pathol Lab Med 139: 819-822, 2015.

31. Weigelt B, Kreike B and Reis-Filho JS: Metaplastic breast carcinomas are basal-like breast cancers: A genomic profiling analysis. Breast Cancer Res Treat 117: 273-280, 2009. 
32. Zhang Y, Toy KA and Kleer CG: Metaplastic breast carcinomas are enriched in markers of tumor-initiating cells and epithelial to mesenchymal transition. Mod Pathol 25: 178-184, 2012.

33. Prat A, Parker JS, Karginova O, Fan C, Livasy C, Herschkowitz JI, $\mathrm{He} \mathrm{X}$ and Perou CM: Phenotypic and molecular characterization of the claudin-low intrinsic subtype of breast cancer. Breast Cancer Res 12: R68, 2010.

34. Reis-Filho JS, Pinheiro C, Lambros MB, Milanezi F, Carvalho S, Savage K, Simpson PT, Jones C, Swift S, Mackay A, et al: EGFR amplification and lack of activating mutations in metaplastic breast carcinomas. J Pathol 209: 445-453, 2006.

35. Tseng WH and Martinez SR: Metaplastic breast cancer: To radiate or not to radiate? Ann Surg Oncol 18: 94-103, 2011.

36. Yu JI, Choi DH, Huh SJ, Ahn SJ, Lee JS, Shin KH, Kwon Y, Kim YB, Suh CO, Kim JH, et al: Unique characteristics and failure patterns of metaplastic breast cancer in contrast to invasive ductal carcinoma: A retrospective multicenter case-control study (KROG 13-7). Clin Breast Cancer 15: e105-e115, 2015.

37. Jin X, Yu D, Guo C, Gong X, Li N and Zhao Y: Metaplastic breast carcinoma: A clinical analysis of 26 cases. Int J Clin Exp Pathol 11: 2112-2117, 2018.

38. Cimino-Mathews A, Verma S, Figueroa-Magalhaes MC, Jeter SC, Zhang Z, Argani P, Stearns V and Connolly RM: A clinicopathologic analysis of 45 patients with metaplastic breast carcinoma. Am J Clin Pathol 145: 365-372, 2016.

39. Fayaz S, Demian GA, Eissa HE, Amanguno H and Abuzalouf S: Metaplastic breast carcinoma: Analysis of 31 cases from a single institute. J Egypt Natl Canc Inst 29: 141-145, 2017.

40. Benson R, Madan R, Julka PK and Rath GK: Metaplastic carcinoma of breast: A case series of seven patients from a tertiary care center and review of literature. Gulf J Oncolog 1: 74-76, 2016.

41. Cha N, Wang S, Lv M, Wang DW, Zhang XJ, Zheng M and Tian LX: Breast metaplastic squamous cell carcinoma diagnosed with fine needle and core biopsy: A case study. Am J Case Rep 19: 203-206, 2018

42. Rakha EA, Coimbra ND, Hodi Z, Juneinah E, Ellis IO and Lee AH: Immunoprofile of metaplastic carcinomas of the breast. Histopathology 70: 975-985, 2017.
43. Zhu H, Li K, Dong DD, Fu J, Liu DD, Wang L, Xu G and Song LH: Spindle cell metaplastic carcinoma of breast: A clinicopathological and immunohistochemical analysis. Asia Pac J Clin Oncol 13: e72-e78, 2017.

44. Salemis NS: Metaplastic carcinoma of the breast with mesenchymal differentiation (carcinosarcoma): A unique presentation of an aggressive malignancy and literature review. Breast Dis 37: $169-175,2018$.

45. Hirose T, Honda J, Bando Y, Sasa M, Hirose Y, Nagao T and Tangoku A: A case of matrix-producing carcinoma of the breast. World J Surg Onc 6: 60, 2008.

46. Rakha EA, Tan PH, Varga Z, Tse GM, Shaaban AM, Climent F, van Deurzen CH, Purnell D, Dodwell D, Chan T and Ellis IO: Prognostic factors in metaplastic carcinoma of the breast: A multi-institutional study. Br J Cancer 112: 283-289, 2015.

47. Lester TR, Hunt KK, Nayeemuddin KM, Bassett RL Jr, Gonzalez-Angulo AM, Feig BW, Huo L, Rourke LL, Davis WG, Valero V and Gilcrease MZ: Metaplastic sarcomatoid carcinoma of the breast appears more aggressive than other triple receptor-negative breast cancers. Breast Cancer Res Treat 131: 41-48, 2012.

48. Zhang Y, Lv F, Yang Y, Qian X, Lang R, Fan Y, Liu F, Li Y, Li S, Shen B, et al: Clinicopathological features and prognosis of metaplastic breast carcinoma: Experience of a major Chinese cancer center. PLoS One 10: e0131409, 2015

49. Yamaguchi R, Horii R, Maeda I, Suga S, Makita M, Iwase T, Oguchi M, Ito Y and Akiyama F: Clinicopathologic study of 53 metaplastic breast carcinomas: Their elements and prognostic implications. Hum Pathol 41: 679-685, 2010.

50. Kaufman MW, Marti JR, Gallager HS and Hoehn JL: Carcinoma of the breast with pseudosarcomatous metaplasia. Cancer 53: 1908-1917, 1984

51. Smith BD, Bellon JR, Blitzblau R, Freedman G, Haffty B, Hahn C, Halberg F, Hoffman K, Horst K, Moran J, et al: Radiation therapy for the whole breast: Executive summary of an American society for radiation oncology (ASTRO) evidence-based guideline. Pract Radiat Oncol 8: 145-152, 2018. 